\title{
Imagine immortal elephants
}

\author{
Stuart L. Pimm
}

Imagine immortal elephants. With a calving interval of c. 4 years, females produce $25 \%$ of their number each year. Half the babies are females, so the growth rate is $12.5 \%$. Elephants are merely long-lived, but this is mathematically close to immortal. Some females are too young or old to breed, so half this, or $c$. $6 \%$ growth rate seems about right, and is. This rough calculation tells us that if we care for elephants, their numbers can double in just over a decade. That quickly becomes a lot of biomass, and it comes in large packets. Conversely, killing more than one in 15 every year will shrink their numbers to extinction. Elephants are a huge conservation problem because both scenarios apply, and they are inextricably connected. This issue of Oryx provides insights into those connections.

IUCN categorizes African savannah elephants as Vulnerable but there are probably more than 460,000 of them. Drinking Windhoek Lager in the pub at Kasane, northern Botswana, you are within a day's drive of 250,000 , almost all unfenced. The talk is about elephants as pests. They kill people and destroy the crops of those whose only option is starve for a year and replant. Elephants hammer natural vegetation too, stripping off everything green by late dry season. How many are too many elephants, especially when in a decade there might be twice as many?

Graham \& Ochieng consider 5,000 elephants in a landscape of smallholder farms in Kenya. Conflicts are numerous, almost one per elephant per year. Half involve crop raiding. Electric fences work, but are too expensive for most farms. Unfortunately, simpler technologies, such as burning homemade briquettes of dried chillies and elephant dung, are not effective.

Investigating elephant movements could provide useful insights. Harris et al. model elephants in moist woodlands along the Indian Ocean and dry steppes in Namibia. Inspired by human patterns of pub use, they find that similarly simple rules apply. 'Elephants prefer to move little, drink easily, eat well, and avoid people'. The problem is that eating well can mean crop raiding in the late wet season, at harvest time. In Botswana's dry season, Jackson et al. find that elephants must drink every night at the Okavango River, their only water source. People live along the river and there are conflicts. After rains, the elephants range more widely.

Are elephant problems getting worse? Junker et al. warn that assessing temporal trends is difficult. Densi- ties apparently remained similar over 20 years in Botswana but the area surveyed increased. Did more money allow surveyors to count more elephants or do elephants now range more widely? Woolley et al. find that how nature stabilizes numbers depends on where mortalities act. When Kruger National Park culled elephants annually, a c. 5\% kill sufficed. They killed all ages, eliminating family groups but they could have had the same demographic effect by killing (or sterilizing) many fewer females on the verge of puberty. Mortalities are not constant, of course: a severe drought per generation will do the trick too.

Elephant populations live on a demographic knife edge where small differences in hard-to-estimate parameters can mean boom or bust. Dunham's 15,000 elephants in northern Zimbabwe appear stable. The cause is a huge recent increase in the number of dead carcasses, probably killed by poachers whose numbers correlate with the carcasses. Yet more poachers and the elephants may crash. In Kasane's pub, talk moves to controlled kills and legal ivory sales to provide more money for anti-poaching and wildlife management units. It's a strong preference in some African countries.

After travelling across a landscape where every square meter is devoted to human use, the short trip across the river into the rainforest of Cat Tien National Park in Vietnam is breathtaking. Fifty meters inside and you cannot see the paddy fields nor, Varma et al. report, the Asian elephants. But they do find dung and, from it, estimate that 17 elephants live here. A world away, and a different species, their fate is linked to what happens in Africa. We drink our Saigon Export, understanding that ivory is ivory, whatever its origin. Poaching puts ivory onto the market, as do legal sales from stockpiles.

Demographics matter here too: of those who carve ivory. Ivory has no immediate value. It gets value only when intricately carved, a skill that requires a lifetime. My simple demographic insight is that a generation without ivory sales would mean no apprentice ivory carvers. That solves the poaching problem but not that of the smallholder waiting to replant his trampled crops. Local elephant conservation is difficult enough, but the problems reside in a global net of ineluctably connected problems.

Stuart L. Pimm

Nicholas School of the Environment E Earth Sciences, Box 90328, Duke University, Durham, NC 27708, USA. E-mail stuartpimm@aol.com 